\title{
Analytical and Experimental Study of Residual Stresses in Thermal Barrier Coatings Deposited on Gas Turbine Blades in Laboratory Dimensions by APS and HVOF Methods to Calculate the Optimal Thickness
}

\author{
Esmaeil Poursaeidi · Farzam Montakhabi · Javad Rahimi
}

Mechanical Engineering Department, Faculty of Engineering, University of Zanjan, Iran.

\begin{abstract}
The constant need to use gas turbines has led to the need to increase turbines' inlet temperature. When the temperature reaches a level higher than the material's tolerance, phenomena such as creep, changes in mechanical properties, oxidation, and corrosion occur at high speeds, which affects the life of the metal material. Nowadays, operation at high temperatures is made possible by proceedings such as cooling and thermal insulation by thermal barrier coatings (TBCs). The method of applying thermal barrier coatings on the turbine blade creates residual stresses. In this study, residual stresses in thermal barrier coatings applied by APS and HVOF methods are compared by Tsui-Clyne analytical model and XRD test. The analytical model results are in good agreement with the experimental results (between 2 and $8 \%$ error), and the HVOF spray method creates less residual stress than APS. In the end, an optimal thickness for the coating is calculated to minimize residual stress at the interface between the bond coat and top coat layers. Special Issue on Asian Thermal Spray Conference (ATSC2020)

CIndian Thermal Spray Society, INScienceIN. 2020.All rights reserved
\end{abstract}

\section{Introduction}

There are two ways to reduce the temperature of gas turbine blades. The first method is cooling and the second method is using thermal barrier coatings [1]. Thermal barrier coatings are usually made of a combination of different layers, each layer having a specific function. The top layer is thermal insulation and is made of ceramic with low thermal conductivity and is usually made of zirconia $\left(\mathrm{ZrO}_{2}\right)$. The ceramic insulation layer is deposited on the substrate metal by an oxidation-resistant metal layer known as the bond coating (BC). During the deposition of top coating (TC), thermal oxide (TGO), mainly $\mathrm{Al}_{2} \mathrm{O}_{3}$, is formed on the surface of the bond layer, which is the interface between this layer and the ceramic coating. In fact, TGO connects the ceramic layer to the bond layer. Therefore, the TBC system includes the ceramic coating, TGO and the metal bond coating on the substrate alloy [2]. Despite the variety of methods for depositing thermal barrier coatings on the substrate, the two methods of atmospheric plasma spray (APS) for the ceramic layer and high-velocity oxygen-fuel spray (HVOF) for the metal bond layer are the most widely used in the industry. Each of these methods creates residual stresses at the coating surface. It is important to be able to measure the residual stress within a deposit in order to control and reduce its build-up by varying the spray parameters [3]. In the following, some researches on thermal barrier coatings are reviewed.

In 1997, Tsui and Clyne developed an analytical model based on force and moment balances to model residual stresses in thermal barrier coatings. This model takes into account the two main residual stress generation mechanisms (intrinsic stress during deposition and differential thermal contraction), allowing their relative contributions to the final residual stress state to be determined. With this model, residual stress distributions can be determined directly by knowing the specimen dimensions, material properties and the intrinsic stress [4]. In 2004, Stokes et al. conducted a study of residual stresses in thick thermal barrier coatings, comparing experimental results with a numerical model and concluding that the success of the spray-forming technique depends on many parameters, which influence residual stress development [3]. In 2006, Martena et al. conducted a research to study the stress distribution in thermal barrier coatings as well as its oxidation and found that the growth rate of TGO at cyclic loading was higher than its growth rate at constant load. Also, with increasing the thickness of TGO, the amount of stress increases [5]. In 2008, Bolleli et al. studied the residual stresses in $\mathrm{Al}_{2} \mathrm{O}_{3}$ and $\mathrm{Cr}_{2} \mathrm{O}_{3}$ ceramic coatings and compared different thermal spray methods and concluded that higher quenching stress is found in plasmasprayed $\mathrm{Al}_{2} \mathrm{O}_{3}$, possibly because of a different lamella solidification and cooling process.They also concluded that contrarily to $\mathrm{Al}_{2} \mathrm{O}_{3}$-based coatings, $\mathrm{Cr}_{2} \mathrm{O}_{3}$-based ones have a much less predictable behavior. They display a much lower surface residual stress, and the HVOF coating also exhibits a marked stress gradient, much higher than the analytically predictable one [6]. In 2014, Jackson and Begley introduced critical cooling rates to prevent cracks in TBCs.They concluded that by sudden cooling of the coating surface, a contraction occurs on the other side of the coating, which in turn causes tensile stress in the coating so that its amount is maximum at the coating surface and its magnitude increases with increasing cooling rate [7]. In 2016, Jiang et al. numerically analyzed the effect of TGO thickness and interlayer roughness on the crack behavior 
at the surface between the interface coating and TGO. Their results showed that the crack behavior due to residual stresses and interlayer roughness during cooling leads to the distribution of stresses around the rough surface of the joints so that the thickness of TGO has a significant effect on the maximum amount of tensile stress [8]. In 2017, Li et al. investigated the distribution of residual stresses in terms of thickness and pore effect on the coating and distortion at the interface between the $\mathrm{BC}$ and $\mathrm{TC}$ layers in APS-sprayed coatings using XRD experiments and imagebased modeling. They found that the pores do not have much effect on the overall residual stress distribution and that distortion at the interface is the main cause of the mutation in the residual stress distribution process [9]. In 2017, the residual stresses in the TBC and TGO layers during the manufacturing process were analyzed by numerical simulation by Bolek et al., and it was concluded that the level of residual stress strongly depends on the differences in the properties of the constituents and the degree of distortion of the TBC layers. Numerical simulations of the real shape of the interface of the layers showed that the concentration of stress occurs not only at the peaks and valleys of the junction but also at the semiflat surface between them [10]. In 2018, Poursaeidi et al. examined the effect of the thickness of the thermally grown oxide layer (TGO) on the thermal shock resistance of thermal barrier coatings (TBCs) and also experimentally evaluated their behavior under a cyclic loading (including aging at maximum temperature). In addition, by conducting an experiment, they investigated the simultaneous effect of TGO growth and the mismatch of thermal expansion on the failure of thermal barrier coatings and concluded that the presence of TGO with a thickness of 2-3 $\mu \mathrm{m}$ had a positive effect on heat shock resistance [2]. In 2018, Jiang et al. numerically studied the stresses in TBC film cooling systems under working conditions, and the results showed that film cooling causes severe thermal changes and uneven growth of the thermally grown oxide layer (TGO) [11]. In 2018, for the first time, the thermal-cycle dependent residual stress in an atmosphere plasma sprayed thermal barrier coating system has been nondestructively and accurately measured using photoluminescence piezo-spectroscopy by Jiang et al. and it was concluded that many microcracks nucleated at different locations and the spallation occurred due to the coalescence of the microcracks [12]. In 2019, Poursaeidi et al. numerically simulated the growth of cracks in the interface of thermal barrier coatings, and the results obtained by the finite element analysis indicated that as the thermal ageing period increased, the interface separation was enlarged and cracks started to nucleate from other points of the interface [13]. In 2019, Song et al. investigated the influence of TGO non-uniform growth on stress evolution and interfacial crack initiation by the finite element method. The results demonstrate that, compared with a uniform growth model, the non-uniform growth of TGO increases the magnitude of residual stress in the TC layers and leads to the early initiation of interfacial cracks. Moreover, the difference in maximum stress between uniform and non-uniform growth increases with the increase in interfacial roughness [14]. In 2020, Abubakar et al. used a hybrid computational approach to predict the evolution of internal cracks and residual stress in TBC. First they used smooth particle hydrodynamics (SPH) to model the deposition of yttria-stabilized zirconia (YSZ) layer that contains various interfaces and micropores on a steel substrate. Then, they utilized three-dimensional (3D) finite element analysis to predict the evolution of internal cracks and residual stress in the ceramic coating layer. It was found that multiple cracks emerge during the solidification of the coating layer due to the development of high tensile (quenching) stresses. The cracking density is higher at regions near the coating interface. It was also found that compressive (residual) stresses are developed when the deposited coating is cooled to room temperature [15]. In this study, the residual stresses in a thermal barrier coating applied by APS method was investigated by Tsui-clyne analytical model and its results were compared with the results of XRD test. Then, by changing the necessary parameters, the two methods of spray, APS and HVOF were compared with each other in terms of residual stress values. An optimal thickness has also been calculated to minimize residual stress between the BC metal layer and the TC ceramic layer.

\section{Experimental}

Analytical modeling of residual stress and comparison with XRD test results

\section{Manufacturing specimens}

Due to the effect of substrate material on the results, the substrate material with the specifications mentioned in Table (1) was considered according to the real samples used in gas turbines. For this purpose, flake specimens with a diameter of $25 \mathrm{~mm}$ and a thickness of $3 \mathrm{~mm}$ were extracted from the first row turbine blade specimen by wire cut method. In order to prevent the concentration of stress due to the increase in temperature at the edges, the edges of all samples were chamfered at an angle of about 45 degrees [16]. An image of the test specimens has been shown in Fig. 1.

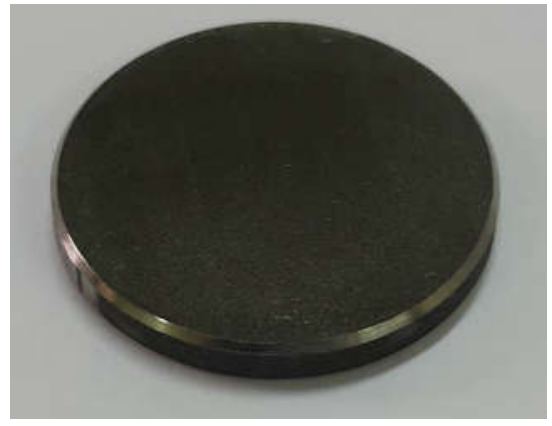

Figure 1: Sample extracted from the root of the turbine blade and the chamfer created on the sharp edge

In order to deposit the coating, after degreasing, the samples were sandblasted with aluminum oxide particles, then placed on a rotating table to apply the interface coating layer on the fixtures. After BC deposition, the samples were placed on the fixtures again and TC coating was deposited [16].

\section{Results and Discussion Growth of TGO layer}

The TGO layer grows during the time exposed to high temperatures, which mainly advances by oxidation of the aluminum present in the BC layer [2]. So far, several theoretical relationships have been extracted to derive the TGO growth trend, such as Itch law [17] and Meier law [18], which are mainly exponential. 
With the formation of this layer, a large residual stress is created between the TC and BC layers due to the mismatch of the thermal expansion coefficients of the ceramic layer and the metal layer of the bond coating [19]. The aging test was performed under load at a constant temperature of $1070^{\circ} \mathrm{C}$ by Poursaeidi et al., which included six sampling steps after $0,12,24,48,72,120$ and 192 hours [16]. High temperature was provided in all experiments by a muffle furnace, Fig. 2.

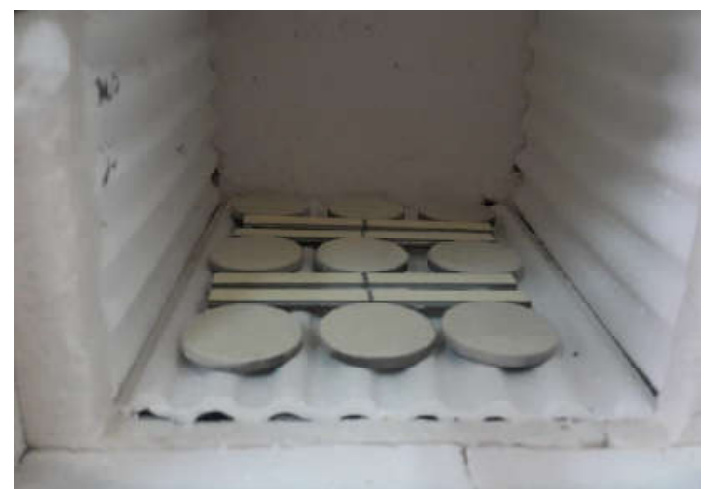

Figure 2: Interior view of the furnace and placement of samples inside the furnace [16]

In the diagram in Fig. 3, the growth trend of the TGO layer obtained through the experiment is plotted and compared with the results of Itch's law and Meier's law.

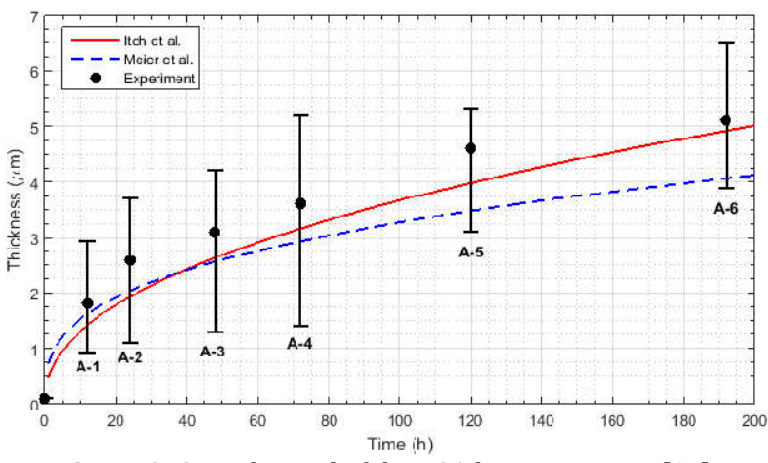

Figure 3: Growth trend of the TGO layer over time [16]

\section{Residual stress measurement by XRD test}

Residual stress measurement in thermal barrier coatings by XRD method has been widely used. The XRD method is based on measuring changes in the distance between crystal lattices. In this method, by radiation a beam of X ray with wavelength $\lambda$ on the sample surface, the $X$ - ray refraction has occurred and will follow the Bragg equation [20].

$$
n \lambda=2 d \sin \theta
$$

In equation (1), $\mathrm{n}$ is the order of reflection, $\mathrm{d}$ is the distance between the crystal plates and $\theta$ is the Bragg angle of refraction. When there is residual stress in a sample, the distance between the crystal planes, $d$, will be different from their distance without stress [20].

The results of the XRD test previously performed by Poursaeidi et al. [16] are shown in Fig. 4.

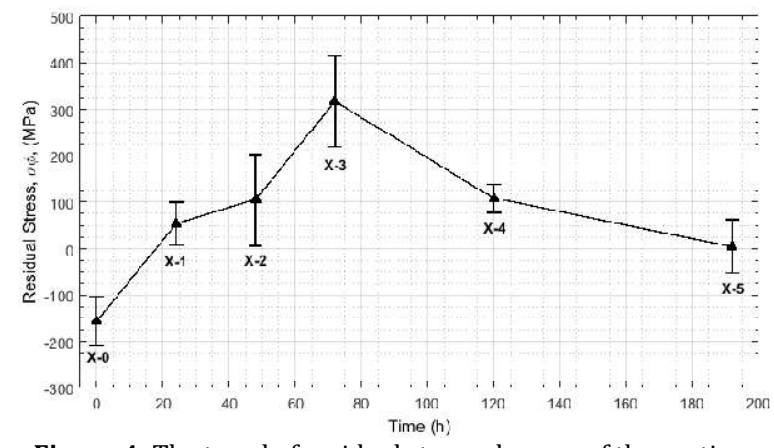

Figure 4: The trend of residual stress changes of the coating surface obtained by XRD test [16]

\section{Tsui-clyne analytical model}

Residual stresses are commonly generated during coating production. Coating performance indicators such as spallation resistance, thermal cycling life and fatigue properties are strongly influenced by residual stresses [4]. Residual stresses arise from two main sources: quench stresses, which are caused by the sudden cooling of molten material upon impact with the substrate during the coating process and cooling stresses that occur after the coating process due to the mismatch of the coefficient of thermal expansion between the coating and the substrate during cooling [4]. Clyne and co-workers used an analytical method, which considers a pair of plates bonded together with a misfit strain $\Delta \varepsilon$ in the $\mathrm{x}$-direction [3]. This model relates to planar geometry [4]. The stresses set up due to the deposition process are considered, followed by those due to CTE mismatch during final cooling to room temperature. It is assumed that the substrate is clamped only at one end and is free to bend during the process [4].

The final residual stress levels at the bottom and top of the substrate are obtained through equations (2) and (3) [4].

$$
\begin{gathered}
\sigma_{\mathrm{sb}}=\left.\sigma_{\mathrm{s}}\right|_{\mathrm{y}=-\mathrm{H}}=\sum_{\mathrm{i}=1}^{\mathrm{n}}\left(\frac{-\mathrm{E}_{\mathrm{s}} \mathrm{F}_{\mathrm{i}}}{\mathrm{b}\left(\mathrm{HE}_{\mathrm{s}}+(\mathrm{i}-1) \mathrm{wE}_{\mathrm{d}}\right.}+\mathrm{E}_{\mathrm{S}}\left(\kappa_{\mathrm{i}}-\kappa_{\mathrm{i}-1}\right)(\mathrm{H}+\right. \\
\left.\left.\delta_{\mathrm{i}}\right)\right)-\frac{\mathrm{F}_{(\mathrm{CTE})}}{\mathrm{bH}}+\mathrm{E}_{\mathrm{s}}\left(\kappa_{\mathrm{c}}-\kappa_{\mathrm{n}}\right)\left(\mathrm{H}+\delta_{\mathrm{n}}\right) \\
\sigma_{s t}=\left.\sigma_{s}\right|_{\mathrm{y}=0}=\sum_{\mathrm{i}=1}^{\mathrm{n}}\left(\frac{-\mathrm{E}_{\mathrm{s}} \mathrm{F}_{\mathrm{i}}}{\mathrm{b}\left(\mathrm{HE}_{\mathrm{s}}+(\mathrm{i}-1) \mathrm{wE}_{\mathrm{d}}\right.}+\mathrm{E}_{\mathrm{S}}\left(\kappa_{\mathrm{i}}-\right.\right. \\
\left.\left.\kappa_{\mathrm{i}-1)}\right) \delta_{\mathrm{i}}\right)-\frac{F_{(C T E)}}{b H}+E_{S}\left(\kappa_{\mathrm{c}}-\kappa_{\mathrm{n}}\right)\left(\delta_{\mathrm{n}}\right)
\end{gathered}
$$

For the deposit, the stress at the midpoint of $\mathrm{j}^{\text {th }}$ layer is, [4]

$$
\begin{gathered}
\sigma_{d \mathrm{j}}=\left.\sigma_{d}\right|_{y=(\mathrm{j}-1 / 2) w}=\frac{F_{j}}{b w}-E_{d}\left(\kappa_{i}-\kappa_{i-1}\right)\left(\left(j-\frac{1}{2}\right) w-\right. \\
\left.\delta_{i}\right)+\sum_{i=j+1}^{n}\left(\frac{-E_{d} F_{i}}{b\left(H E_{S}+(i-1) w E_{d}\right.}-E_{d}\left(\kappa_{i}-\kappa_{i-1}\right)\left(\left(j-\frac{1}{2}\right) w-\right.\right. \\
\left.\left.\delta_{i}\right)\right)+\frac{F_{(C T E)}}{b H}-E_{d}\left(\kappa_{\mathrm{c}}-\kappa_{\mathrm{n}}\right)\left(\left(j-\frac{1}{2}\right) w-\delta_{n}\right)
\end{gathered}
$$

The inputs intended for this model are shown in Table (1).

Table1:Tsui-Clyne analytical model inputs[16]

\begin{tabular}{lcccc}
\hline & $\begin{array}{c}\text { Top Coat } \\
\mathrm{ZrO}_{2} \\
-8 \% \mathrm{wtY}_{2} \mathrm{O}_{3}\end{array}$ & $\begin{array}{c}\text { Oxide Layer } \\
\alpha-\mathrm{Al}_{2} \mathrm{O}_{3}\end{array}$ & $\begin{array}{c}\text { Bond Coat } \\
\text { (NiCoCrAlY) }\end{array}$ & Substrate \\
\hline $\begin{array}{l}\text { Young's } \\
\text { modulus (GPa) }\end{array}$ & 22 & 320 & 110 & 184 \\
$\begin{array}{l}\text { Poisson's ratio } \\
\text { Thermal } \\
\text { expansion } \\
\text { coefficient } \\
\alpha \times 10^{-6}\left({ }^{\circ} \mathrm{C}^{-1}\right)\end{array}$ & 0.12 & 0.25 & 0.33 & 0.30 \\
Thickness & 12.2 & 9.6 & 17.6 & 16.3 \\
\hline
\end{tabular}




\section{Comparison of results}

The results of the residual stress measurement of the coating surface by the Tsui-Clyne analytical model are shown in Fig. 5.

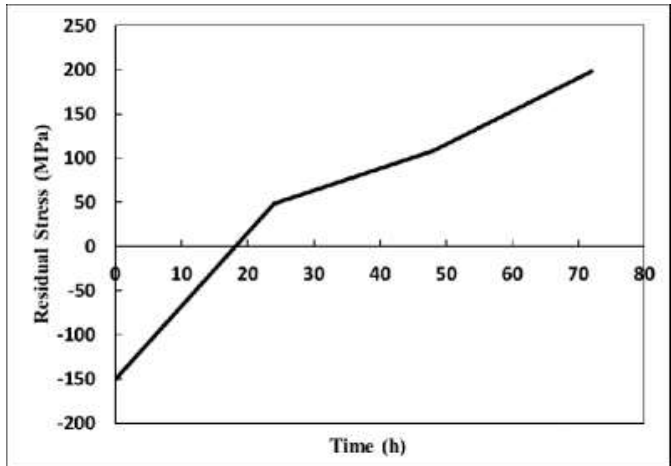

Figure 5: Residual stress level diagram of coating surface in terms of time, calculated by analytical modeling

Table (2) compares the results of the Tsui-Clyne analytical model with the results of the XRD test and shows that the error is between $2-8 \%$ by 48 hours, but after that the results of the analytical model do not match the experimental results.

Table 2: Comparison of experimental results with analytical modeling

\begin{tabular}{ccccc}
\hline Time (h) & 0 & 24 & 48 & 72 \\
& & & & \\
$\begin{array}{c}\text { Method or } \\
\text { measurement }\end{array}$ & & & & \\
\hline XRD test (MPa) & -154.10 & 52.28 & 106.7 & 317.62 \\
\hline $\begin{array}{c}\text { Analytical } \\
\text { model (MPa) }\end{array}$ & -150.64 & 48.59 & 108.36 & 198.13 \\
\hline
\end{tabular}

\section{Comparison of residual stresses generated by APS and HVOF spray methods}

In the APS process, the coating powder is injected into the plasma flame and melted and thrown into the substrate; after colliding the substrate, the particles quench and harden. A coating system is produced by repeating these collisions to the substrate [21]. The HVOF process is one of the most advanced spraying systems created within a gas jet and using the blast wave in its internal combustion chamber, it is able to apply carbide particles at a speed of about 1200 to 1500 meters per second (approximately five times the speed of sound) on the surfaces of the desired parts[22].

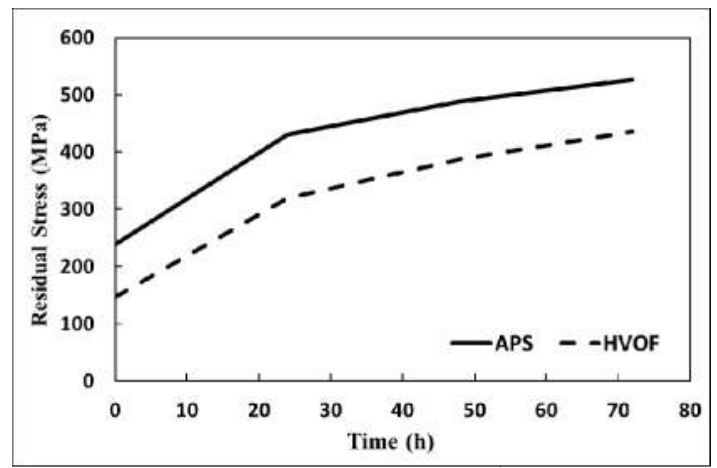

Figure 6: Bond coating residual stress diagram in terms of time, calculated by analytical model for APS and HVOF spray methods
Using the Tsui-Clyne analytical model, by changing theintrinsic quench stress parameter $\left(\sigma_{q}\right)$ and temperature changes during cooling $(\Delta \mathrm{T})$, the two spray methods APS and HVOF were compared in terms of the amount of residual stress in the $\mathrm{BC}$ layer.The residual stress diagram in terms of time is shown in Fig. 6.

\section{Calculation of the optimal thickness for the TC layer} At $\mathrm{t}=0$, when the TGO layer has not yet grown, the residual stress at the interface of the BC and TC layers at different thicknesses of the TC layer, between 200 and 350 microns, was calculated and considering that by increasing the thickness of the TC layer, the residual stress increases and changes from the compressive state to the tensile state in the interface, the stress-free state was considered as the optimal thickness. Fig. 7 shows the residual stress diagram at the interface of the $\mathrm{BC}$ and $\mathrm{TC}$ layers in terms of thickness.

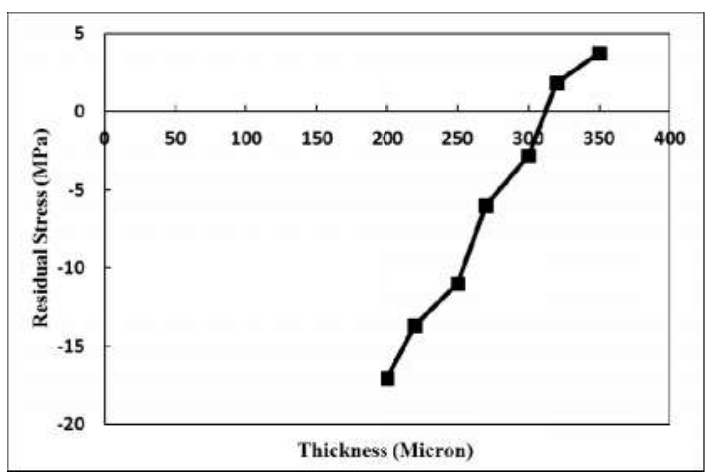

Figure 7: Residual stress diagram at the interface of BC and TC layers in terms of thickness

It is observed that the residual stress in the thickness between 300 and 320 microns has passed the zero point (stress free). With linear interpolation method; the thickness of 312 microns is calculated as the optimal thickness for the TC layer.

\section{Analysis of results}

According to the residual stress diagram obtained through XRD test, it was observed that the residual stress of the coating surface at the moment $\mathrm{t}=0$ is compressive, but after the growth of TGO layer due to different thermal expansion coefficient during cooling, tensile stress is applied to TC layer and the stress changes from the compression to the tensile state. After 72 hours, the residual stress decreases due to the growth of cracks that release the stress. Residual stress was modeled by the Tsuai-Clyne analytical model for up to 72 hours because it did not consider crack growth and release of residual stress.It was observed that the results of the analytical model show good agreement with the results of XRD test up to 48 hours (between 2 and 8\% error), but after 48 hours, because the analytical model considers the geometry of the coating to be completely flat, in reality the geometry of the TGO layer is distorted and sinusoidal, and the uneven growth of the TGO will cause residual stresses, also, considering that in this model, only the growth of the TGO layer is considered in the direction of thickness (normal growth) and the lateral growth of the TGO layer also causes a lot of residual stress, the results of the model show a big difference with the test results. 
By changing the required parameters (intrinsic quench stress $\left(\sigma_{q}\right)$ and temperature changes during cooling $(\Delta \mathrm{T})$ ), the residual stress created in the thermal barrier coating in APS and HVOF thermal spray methods were compared byTsui-Clyne analytical model and according to the diagram of Fig. 6, it was concluded that the HVOF method creates less residual stress than the APS method because the quench stress values are generated and the temperature changes in the HVOF method are less than the APS method, so it is a more suitable method for thermal spraying of thermal barrier coatings.

Finally, at the moment $t=0$, when the thermally grown oxide layer (TGO) has not yet grown, the residual stresses at the interface between the $\mathrm{BC}$ and TC layers in terms of TC layer thickness between 200 and 350 microns were calculated by Tsui-Clyne analytical model. According to the diagram in Fig. 7, it was observed that with increasing the thickness of the TC layer, the residual stress increases and due to the fact that the stress changes from the compressive state to the tensile state,the stress-free state at a thickness of 312 microns was calculated by the linear interpolation method as the optimal thickness for the TC ceramic layer.

\section{Conclusions}

In this study, residual stresses in a thermal barrier coating applied by APS method were modeled using Tsui-Clyne analytical model and compared with XRD test results and it was observed that it shows good agreement with the test results up to 48 hours (between 2 to $8 \%$ error) but after 48 hours, the model results show a big difference with the test results.

By changing the necessary parameters, the residual stress of the coating in the two methods of thermal spray APS and HVOF were compared using the Tsui-Clyne analytical model and it was concluded that the HVOF method creates less residual stress than the APS, so it is a more suitable method for thermal spraying of thermal barrier coatings. Finally, at the moment $t=0$, the residual stresses at the interface between the $\mathrm{BC}$ and TC layers in terms of TC layer thickness between 200 and 350 microns were calculated by Tsui-Clyne analytical model and the stress-free state at a thickness of 312 microns was calculated by the linear interpolation method as the optimal thickness for the TC ceramic layer.

\section{References}

1. Rahimi, J., Poursaeidi, E., Khavasi, E. Stress analysis of a second stage gas turbine blade under asymmetric thermal gradient. Mechanics \& Industry, 2019, 20(6), 607.

2. Torkashvand, K., Poursaeidi, E., Mohammadi, M. Effect of TGO thickness on the thermal barrier coatings life under thermal shock and thermal cycle loading. Ceramics International, 2018, 44(8), 9283-9293.

3. Stokes, J., L. Looney. Residual stress in HVOF thermally sprayed thick deposits." Surface and Coatings Technology, 2004, 177: 18-23.

4. Tsui, Y. A. C., Clyne, T. W. An analytical model for predicting residual stresses in progressively deposited coatings Part $1:$ Planar geometry. Thin solid films, 1997, 306(1), 23-33.

5. Martena, M., Botto, D., Fino, P., Sabbadini, S., Gola, M. M. Badini, C. Modelling of TBC system failure: Stress distribution as a function of TGO thickness and thermal expansion mismatch. Engineering Failure Analysis, 2006, 13(3), 409-426.

6. Bolelli, G., Lusvarghi, L., Varis, T., Turunen, E., Leoni, M Scardi, P., Barletta, M. Residual stresses in HVOF-sprayed ceramic coatings. Surface and Coatings Technology, 2008, 202(19), 4810-4819.

7. Jackson, R. W., Begley, M. R., Critical cooling rates to avoid transient-driven cracking in thermal barrier coating (TBC) systems. International Journal of Solids and Structures, 2014, 51(6), 1364-1374.

8. Jiang, J., Xu, B., Wang, W., Adjei, R. A., Zhao, X., \& Liu, Y. Finite element analysis of the effects of thermally grown oxide thickness and interface asperity on the cracking behavior between the thermally grown oxide and the bond coat.Journal of Engineering for Gas Turbines and Power, 2017, 139(2).

9. Li, C., Zhang, X., Chen, Y., Carr, J., Jacques, S., Behnsen, J., Cernik, R.. Understanding the residual stress distribution through the thickness of atmosphere plasma sprayed (APS) thermal barrier coatings (TBCs) by high energy synchrotron XRD; digital image correlation (DIC) and image based modelling. Actamaterialia, 2017, 132, 1-12.

10. Bolek, T., Sitek, R., Sienkiewicz, J., Dobosz, R., Mizera, J., Kobayashi, A., Kurzydlowski, K. J. Simulation of the influence of the interface roughness on the residual stresses induced in (ZrO2+ Y2O3)+NiAl-type composite coatings deposited on Inconel 713C. Vacuum, 2017, 136, 221-228.

11. Jiang, J., Jiang, L., Cai, Z., Wang, W., Zhao, X., Liu, Y., Cao, Z. Numerical stress analysis of the TBC-film cooling system under operating conditions considering the effects of thermal gradient and TGO growth. Surface and Coatings Technology, 2019, 357, 433-444.

12. Jiang, P., Fan, X., Sun, Y., Wang, H., Su, L., Wang, T. Thermal-cycle dependent residual stress within the crack-susceptible zone in thermal barrier coating system. Journal of the American Ceramic Society, 2018, 101(9), 4256-4261.

13. Mohammadi, M., Poursaeidi, E., Torkashv, K. Finite element analysis of the effect of thermal cycles and ageing on the interface delamination of plasma sprayed thermal barrier coatings. Surface and Coatings Technology, 2019, 375, 243255.

14. Song, J., Qi, H., Shi, D., Yang, X., Li, S. Effect of non-uniform growth of TGO layer on cracking behaviors in thermal barrier coatings: A numerical study. Surface and Coatings Technology, 2019, 370, 113-124.

15. Abubakar, A. A., Arif, A. F. M., Akhtar, S. S. Evolution of internal cracks and residual stress during deposition of TBC. 2020, Ceramics International, 46(17), 26731-26753.

16. Mohammadi, M., Poursaeidi, E. Failure mechanisms and their finite element modeling of air plasma spray thermal barrier coatings: A review. 2019, Advanced Materials and Novel Coatings, 7(27), 1937-1953.

17. Birks, N., Meier, G. H., Pettit, F. S. Introduction to the high temperature oxidation of metals. 2006, Cambridge University Press.

18. Meier, S. M., Nissley, D. M., Sheffler, K. D., Cruse, T. A. Thermal barrier coating life prediction model development. In Turbo Expo: Power for Land, Sea and Air, 1991, 79023, V005T13A003.

19. Bartsch, M., Marci, G., Mull, K., \& Sick, C. Fatigue testing of ceramic thermal barrier coatings for gas turbine blades. 1999, Advanced Engineering Materials, 1(2), $127-$ 129.

20. Noyan, I. C., Cohen, J. B. Residual stress: measurement by diffraction and interpretation. 2013, Springer.

21. Vaßen, R., Kaßner, H., Stuke, A., Hauler, F., Hathiramani, D., Stöver, D. Advanced thermal spray technologies for applications in energy systems. Surface Coat Tech., 2008, 202(18), 4432-4437.

22. Kuroda, S., Fukushima, T. (2005). U.S. Patent Application No $10 / 515,816$

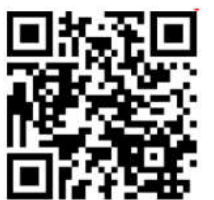

